\title{
AXIAL CRUSHING OF GFRP FRUSTA: EXPERIMENTAL AND NUMERICAL ANALYSIS
}

\author{
Mohammed A. K., M. Naushad Alam, Raisuddin Ansari \\ Department of Mechanical Engineering \\ Zakir Husain College of Engineering \& Technology \\ Aligarh Muslim University, Aligarh, UP, 202002, India
}

\begin{abstract}
Experimental and numerical analysis of the axial crushing of glass fiber reinforced polymer (GFRP) frusta tubes are presented in this study. The frusta tubes are fabricated from plain woven C-glass fabric bonded with the epoxy system LY-556 resin and HY951 hardener. Two semi-apical angles $5^{\circ}$ and $10^{\circ}$ with $95 \mathrm{~mm}$ height and $1.4 \mathrm{~mm}$ wall thickness were studied under quasi-static crush conditions. All specimens showed progressive damage in region starts from the contact with the crushing crosshead and spreads about $7 \mathrm{~mm}$ ahead the crushing surface. Mix of tiny debris and strip shaped chunks are generated in the crushing zone. The debris is accumulated as outside or inside fronds formation. The strip shaped chunks are generated peripherally due to shear effects by crusting from the frusta body and crack growth at the outmost crush zone points from the crushing surface. The $5^{\circ}$ frusta showed better crashworthiness performance than $10^{\circ}$ frusta. Simulation results showed good agreement with the experimental findings in both collapse mode and energy absorption.
\end{abstract}

Keywords: Crashworthiness, Frusta tubes, GFRP, Progressive damage

Cite this Article: Mohammed A. K., M. Naushad Alam, Raisuddin Ansari, Axial Crushing of GFRP Frusta: Experimental and Numerical Analysis, International Journal of Advanced Research in Engineering and Technology, 10 (2), 2019, pp 491-502. http://iaeme.com/Home/issue/IJARET?Volume=10\&Issue $=2$

\section{INTRODUCTION}

Composite structural elements have very good potentials as energy absorbing elements. Their high strength to weight, stiffness to weight ratios, progressive damage mode, etc. put them in competition with the other structural element types. An anisotropic damage model was presented by Lapczyk and Hurtado [1] for predicting failure and post-failure characteristics in fiber-reinforced materials. They used linear elastic-brittle material model. S2-glass fiber-epoxy structures response investigated under ballistic impact condition by [2,3]. Nested inserts combined into composite sandwich structures are presented by Tarlochan and Ramesh [4]. The tested composite specimens are fabricated from glass and carbon fiber-epoxy. High energy absorption achieved with the progressive failure (primary) mode. Linde et al. [5] presented experimental and numerical model for inter rivet buckling of hybrid glass fiber-aluminum laminate. Hybrid composites of metal and fiber-epoxy thin walled structures are studied for different structural elements configurations by $[5,6,7,8]$. Buragohaina and Velmurugan [9] have presented experimental and numerical comparison for axial compression response. The studied 
structures were three types: unstiffened cylindrical shell, lattice cylinder and grid-stiffened cylindrical shell. Circular and corrugated composite tubes were investigated under axial crush conditions by Abdewi et al. [10]. The specimens made from woven glass fiber-epoxy laminated composites. The results showed that the corrugated tubes exhibited higher energy absorption capability compared to cylindrical tubes. Paz et al. [11] have performed finite element axial crush analysis on square steel tubes filled with glass fiber honey comb structured composite. Multi-objective optimization was done to optimize the energy absorption, mass and peak load. Experimental and analytical investigation of aluminum/GFRP hybrid tubes under bending collapse and axial crush conditions are presented by Shin et al. [12]. The structures were aluminum square tubes wrapped by glass fiber-epoxy prepregs. Experimental and numerical performance analysis for GFRP composites and hybrid (metal- GFRP composite) thin walled frusta tubes under axial compression were presented by $[13,14,15]$. In the present work the crashworthiness performance of the GFRP frusta tubes is studied experimentally and numerically under quasi-static crushing conditions. Experimental results along with simulation results are presented and discussed.

\section{CRASHWORTHINESS PARAMETERS}

Crashworthiness parameters are indicators for the structure performance during crushing process. Some of these parameters are briefly explained as:

Energy absorption $\left(E_{a b}\right)$ is the total amount of energy absorbed during the crushing process. Mean crushing force $\left(P_{m}\right)$ is the total energy absorbed divided by the total displacement. Peak crushing force $\left(P_{\max }\right)$ is the maximum resisting load against the crushing crosshead during the whole deformation process. Specific energy absorption $(S E A)$ is an indicator for the structure mass usefulness for energy absorption. It may be defined as the total energy absorbed divided by the crushed mass. The goal of the designers is to maximize the $S E A$ as much as possible.

\section{EXPERIMENTAL WORK}

The steps of the experimental work are as follows:

\subsection{Fabrication of Specimens}

The frusta shaped specimens are fabricated from C-glass fiber plain woven fabric. The fabric cut into trapezoidal shaped pieces according to specified measurements. Four pieces cover one layer with some overlap of the adjacent pieces; Figure 1( $a)$ shows the fabric cuts. The fabric warp direction aligned with the frusta axis. The epoxy system of LY-556 resin and HY951 hardener used to impregnate the glass-fiber fabric. Hand layup method used to place the epoxy saturated fabric cuts on the wooden mandrel. Polyvinyl alcohol and release wax applied on the mandrel to enable easy removal of mandrel parts. Silicon saturated release fabric put on the outside of the epoxy saturated fabric cuts. Breath layer added externally to allow the removal of trapped air and fumes and to absorb the excess epoxy. Thereafter the specimens are subjected to vacuum and left for curing for 24 hours at the ambient temperature. After the specimen curing, the mandrel removed by disassembling and trimming the excess frusta height from both sides up to getting the required dimensions. Figure $1(b$ and $c)$ show samples of frusta to be tested.

\subsection{Mandrel}

A wooden mandrel used as a core where the epoxy saturated fabric cuts are laid up on the periphery. The mandrel fabricated on the lathe machine so that the internal dimensions of the frusta match the mandrel dimensions. The mandrel is drilled centrally and divided into four parts where these parts can be disassembled from the interior side of the cured specimen. The four quarters of the mandrel are supported from the center side by auger shaped cylindrical part 
to keep ventilation between the mandrel sides. Figure 2 shows the assembly and parts of the mandrel for $10^{\circ}$ specimens. Disassembling the mandrel from the cured specimen is sequentially done by (i) removing the auger core, (ii) removing the spacing plates and (iii) removing the wooden parts.

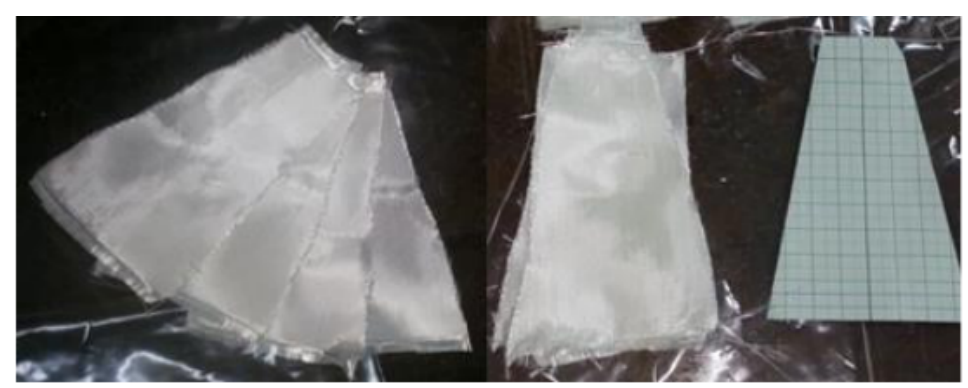

(a)

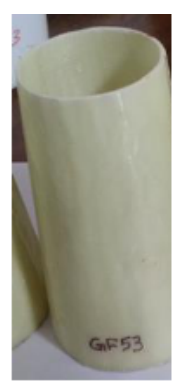

(b)

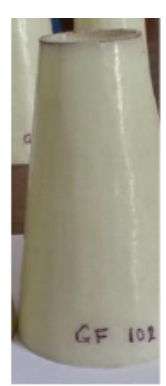

(c)

Figure 1 GFRP frusta: $(a)$ woven glass fibre cuts, $(b)$ specimen with $\alpha=5^{\circ},(c)$ specimen with $\alpha=10^{\circ}$.

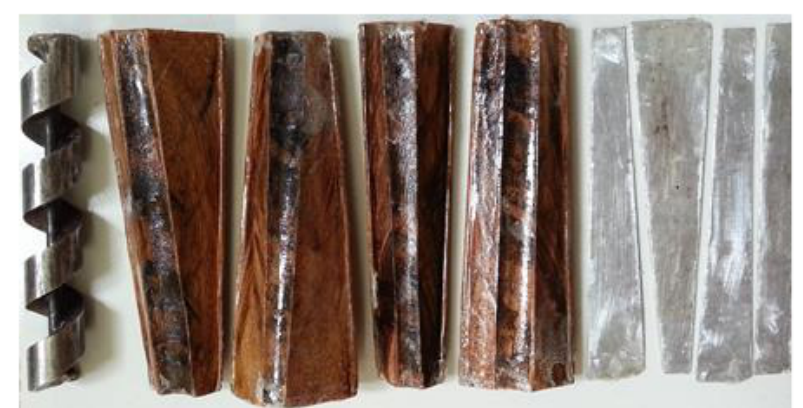

(a)

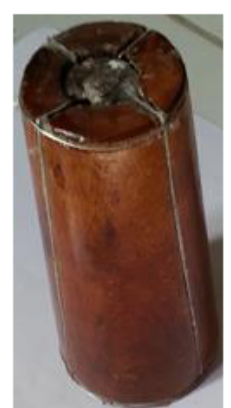

(b)

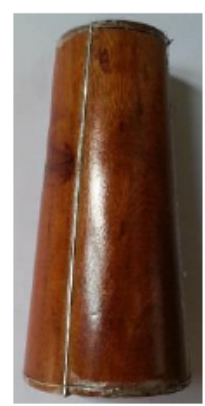

(c)

Figure 2 Mandrel of $\alpha=5^{\circ}$ configuration: $(a)$ parts, $(b)$ assembled mandrel isometric view, $(c)$ assembled mandrel front view.

\subsection{Specimens}

The geometry of the structure under investigation is a frustum tube with two semi-apical angles ( $\alpha) 5^{\circ}$ and $10^{\circ}$. The typical dimensions of the frusta tubes are shown in Figure 3( $a$ and $\left.b\right)$. The dimensional characteristics of the fabricated and tested specimens are shown in Table $\mathbf{1}$. Samples of specimens to be tested are shown in Figure 1( $b$ and $c)$. Damage triggering done by chamfering the frusta smaller ends with $45^{\circ}$ angle.

Table 1 Dimensions of tested frusta specimens

\begin{tabular}{|c|c|c|c|c|c|c|c|}
\hline \multirow{2}{*}{$\begin{array}{c}\text { Sample } \\
\text { Code }\end{array}$} & \multirow{2}{*}{$\begin{array}{c}\text { Height } \\
(\mathbf{m m})\end{array}$} & $\begin{array}{c}\text { Semi- } \\
\text { apical } \\
\text { angle }\end{array}$ & \multicolumn{2}{|c|}{ Larger side (mm) } & \multicolumn{2}{|c|}{ Smaller side (mm) } & \multirow{2}{*}{$\begin{array}{c}\text { Weight } \\
\text { (g) }\end{array}$} \\
\hline GF52 & 95.38 & $5^{\mathbf{0}}$ & 64.7 & 1.39 & 47.9 & 1.41 & 48.74 \\
\hline GF53 & 95.22 & $5^{\mathbf{0}}$ & 64.3 & 1.42 & 48.3 & 1.44 & 49.16 \\
\hline GF54 & 95.71 & $5^{\mathbf{0}}$ & 64.2 & 1.38 & 48.2 & 1.39 & 47.95 \\
\hline GF101 & 95.46 & $10^{\mathbf{0}}$ & 64.6 & 1.40 & 31.4 & 1.43 & 40.77 \\
\hline GF103 & 95.91 & $10^{\mathbf{0}}$ & 64.8 & 1.42 & 30.7 & 1.48 & 42.21 \\
\hline GF104 & 95.53 & $10^{\mathbf{0}}$ & 64.5 & 1.41 & 31.8 & 1.47 & 41.96 \\
\hline
\end{tabular}




\section{CONSTITUTIVE MODEL FOR THE SIMULATION OF WOVEN FABRIC-REINFORCED COMPOSITES}

Elastic-brittle material with anisotropic behavior is generally considered for modeling the damage of GFRP composites. The most convenient material model for such materials is the inplane orthotropic (2D orthotropic) [16]. Abaqus contain's damage model for fiber-reinforced composites enabling the prediction of damage onset and damage evolution. The damage model requires to specify: Undamaged material response, damage initiation response, damage evolution response and element removal from the solution. The anisotropic damage model available in Abaqus is based on the work of Hashin and Rotem [17], Hashin [18], Matzenmiller et al. [19] and Camanho and Davila [20]. Different failure modes are considered in damage modeling. They include fiber rupture due to tension, fiber buckling and kinking due to compression, matrix cracking due to transverse tension and shearing and matrix crushing due to transverse compression and shearing.

\subsection{Mechanics of Elastic Continuum Damage}

This model assumes that each lamina composed of orthogonal woven fabric reinforcement. The formulation of the constitutive stress-strain model performed implementing local Cartesian coordinate system. The base vectors aligned along the fiber directions. The in-plane (intralaminar) elastic stress-strain relations are formulated on the basis of orthotropic damaged elasticity [21]:

$$
\left\{\begin{array}{c}
\varepsilon_{11} \\
\varepsilon_{22} \\
\varepsilon_{12}^{\mathrm{el}}
\end{array}\right\}=\left[\begin{array}{ccc}
\frac{1}{\left(1-\mathrm{d}_{1}\right) \mathrm{E}_{1}} & -\frac{\mathrm{v}_{12}}{\mathrm{E}_{1}} & 0 \\
-\frac{\mathrm{v}_{21}}{\mathrm{E}_{2}} & \frac{1}{\left(1-\mathrm{d}_{2}\right) \mathrm{E}_{2}} & 0 \\
0 & 0 & \frac{1}{\left(1-\mathrm{d}_{12}\right) 2 \mathrm{G}_{12}}
\end{array}\right]\left\{\begin{array}{c}
\sigma_{11} \\
\sigma_{22} \\
\sigma_{12}
\end{array}\right\}
$$

where $\varepsilon_{11}, \varepsilon_{22}, \varepsilon_{12}^{\mathrm{el}}$ are in-plane elastic strains; $\sigma_{11}, \sigma_{22}, \sigma_{12}$ are in-plain elastic stresses; $\mathrm{E}_{1}$ and $\mathrm{E}_{2}$ are the Young's moduli in the principal orthotropic directions; $\mathrm{v}_{12}$ and $\mathrm{v}_{21}$ are the Poisson's ratios in the principal directions; $G_{12}$ is the in-plane shear modulus; $d_{1}$ and $d_{2}$ are the damage parameters associated with fiber fracture along the principal orthotropic directions; $d_{12}$ is the damage parameter associated with the matrix micro-cracking due to the in-plane shear deformation.

$$
\mathrm{d}_{\mathrm{i}}=\mathrm{d}_{\mathrm{i}+} \frac{\left\langle\sigma_{\mathrm{ii}}\right\rangle}{\left|\sigma_{\mathrm{ii}}\right|}+\mathrm{d}_{1-} \frac{\left\langle-\sigma_{\mathrm{ii}}\right\rangle}{\left|\sigma_{\mathrm{ii}}\right|}
$$

where $(i=1,2) ; d_{i+}, d_{i-}$ are the damage variables under tensile and compressive conditions in the ith directions respectively.

The laminated composite material response is categorized into fiber and interface response respectively.

\subsection{Fiber Response}

The fiber damage variables are assumed to be functions for their corresponding effective stresses $\widetilde{\sigma}_{j}$ as in the following equations:

$$
\mathrm{d}_{\mathrm{j}}=\mathrm{d}_{\mathrm{j}}\left(\widetilde{\sigma}_{\mathrm{j}}\right)
$$

where $(\mathrm{j}=1+, 1-, 2+, 2-)$, plus and minus signs are referring to tension and compression respectively.

The damage evolution variables are given by the following expression [22]: 


$$
d_{j}=1-\frac{1}{r_{j}} \exp \left[\frac{-2 g_{0}^{j} L_{c}}{G_{f}^{j}-g_{0}^{j} L_{c}}\left(r_{j}-1\right)\right]
$$

where $r_{j}$ are the damage thresholds which depend upon fiber failure criterion functions and damage activation functions; $L_{c}$ is the characteristic length of the element; $G_{f}^{j}$ is the fracture energy per unit area under uniaxial tensile or compressive loading; $g_{0}^{j}$ is the elastic energy per unit volume (elastic energy density) at the point of damage initiation.

\subsection{Shear Model (Interface Response)}

The nonlinear behavior of the matrix is dominated by the in-plane shear response. Plasticity and micro-cracking are the reasons for the nonlinear behavior exhibited by the matrix. The response of the shear damage is discussed in three groups:

\subsubsection{Elasticity}

The effective (undamaged) stress is formulated in terms of in-plain elastic shear strain $\varepsilon_{12}^{\text {el }}$ as:

$$
\widetilde{\sigma}_{12}=\frac{\sigma_{12}}{\left(1-\mathrm{d}_{12}\right)}=2 \mathrm{G}_{12} \varepsilon_{12}^{\mathrm{el}}
$$

\subsubsection{Plasticity}

In-plane perminant deformation of the lamina upon unloading occur due to matrix inelastic response (cracking or plasticity). These effects can be accounted by associationg the classical physical model, hardening law and elastic domain function. they are applied to the effective stress $\widetilde{\sigma}$ in the damaged material. The elastic domain function (F) distingwish's the plasticity which is formulated as:

$$
\mathrm{F}=\left|\widetilde{\sigma}_{12}\right|-\widetilde{\sigma}_{0}\left(\bar{\varepsilon}^{\mathrm{pl}}\right) \leq 0
$$

the hardening formula is assumed to correlate to the effective initial yield stress and equivalent plastic strain as:

$$
\widetilde{\sigma}_{\mathrm{o}}\left(\bar{\varepsilon}^{\mathrm{pl}}\right)=\widetilde{\sigma}_{\text {yo }}+\mathrm{C}\left(\bar{\varepsilon}^{\mathrm{pl}}\right)^{\mathrm{p}}
$$

where $\mathrm{p}$ and $\mathrm{C}$ are coefficients; $\widetilde{\sigma}_{\mathrm{yo}}$ is the initial effective shear stress; $\bar{\varepsilon}^{\mathrm{pl}}$ is the equivalent plastic strain due to shear deformation. The parameters $\mathrm{C}, \mathrm{p}$ and $\widetilde{\sigma}_{\text {yo }}$ are measured experimentally on $\pm 45^{\circ}$ laminates by conducting cyclic tensile tests [23].

\subsubsection{Damage}

Logarithmic correlation (increase) is assumed between the shear damage variable $d_{\alpha}$ and shear damage threshold $r_{12}$ until the maximum value of damage variable is reached, i.e.

$$
\mathrm{d}_{12}=\min \left(\alpha_{12} \ln \left(\mathrm{r}_{12}\right), \mathrm{d}_{12}^{\max }\right)
$$

where $d_{12}^{\max } \leq 1, \alpha_{12}>0$ and $S_{\text {sh }}$ are material properties and can be obtained experimentally from $\pm 45^{\circ}$ laminated specimens by conducting cyclic tensile tests [23].

\subsection{Maximum degradation and element deletion}

The failed continuum shell elements have to be deleted to overcome the problem of premature termination of the analysis. The deletion is performed in two stages:

- Deleting the individual elements whenever reach the fully damaged condition as ascertained by damage variables $d_{\max }$. The upper bond of the damage variable value is 1 which can be reduced by the user for better controlling the damage conditions. 
- Deleting the separated parts (debris, chunks,...) whenever they are away enough from the crush zone. Leaving these parts in the simulation process causes excessive unphysical distortion for some elements; that's also leads premature termination of the analysis. VUSDFLD Abaqus user's subroutine is implemented to delete all elements and debris whenever they pass the surrounding surfaces.

\section{SIMULATION}

The frusta are modeled as orthotropic laminated part confined between two rigid surfaces. The simulation model is prepared and analyzed using Abaqus 6.19. The user's interface subroutine VUMAT invoked with the material model ABQ_PLY_FABRIC_GFRP LAMINATE. Each ply of the woven fabric is modeled as a homogeneous orthotropic material, with the capability of sustaining plastic deformation under shear load and progressive stiffness degradation due to fiber/matrix cracking [23].

\subsection{Geometry and Boundary Conditions}

The geometry of the studied structure is a frustum tube with two semi-apical angles $(\alpha) 5^{\circ}$ and $10^{\circ}$. Two Abaqus models are prepared for each angle $\alpha$. The models are composed of seven layers each layer is modeled as a separate part. These layers are bonded together by cohesive interface with potentials of progressive damage. The dimensional characteristics of the whole models are illustrated in Figure 3( $a$ and $b)$. The experimentally tested specimens are showed formation of tiny particles and strip shaped debris which are generally small see 6.1 . It is reasonable to make benefit of the symmetry and model one quarter of the frustum tube for each configuration to save the unnecessary computational cost, see Figure 3(c and $d)$. Cylindrical coordinate system with the origin point at the center of the frusta's larger ends used to define material orientation. The z-axis is aligned with the frusta axes and the boundary conditions symmetry is considered with the $r$ and $\theta$ axes of the cylindrical coordinate system. Constant velocity of $200 \mathrm{~mm} / \mathrm{s}$ boundary condition is applied along the frustum axis while restricting all the other degrees for the crushing surface. Encastre boundary condition is applied on the other rigid surface. The specimens are hold in place by the virtue of frictional forces only. Coefficient of friction of 0.15 is used for all contacts in the simulations. Definition of the elements interior surfaces was performed by manual editing the input file.

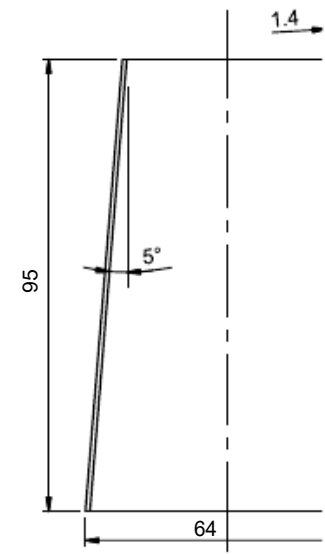

(a)

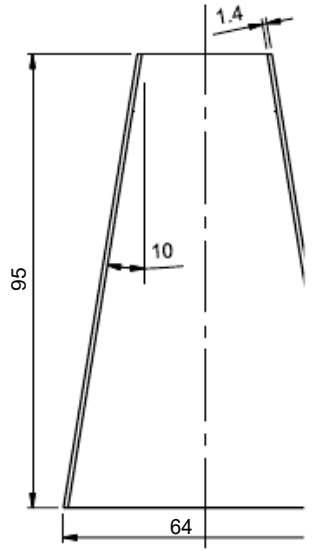

(b)

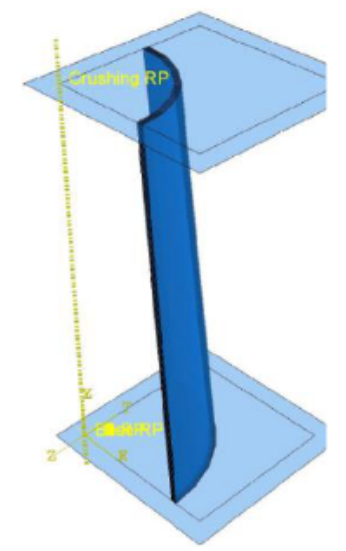

(c)

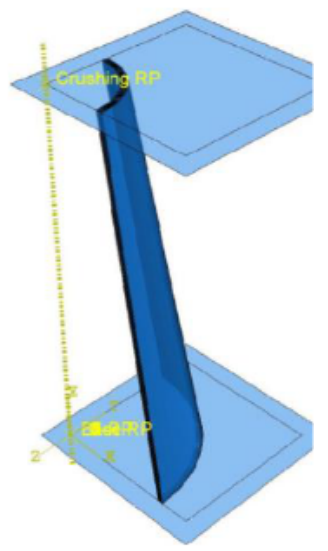

(d)

Figure 3. Frusta dimensions (mm) and Abaqus model for: (a) dimensions for $\alpha=5^{\circ} ;(b)$ dimensions for $\alpha=10^{\circ}$; (c) Abaqus model for $\alpha=5^{\circ}$; (d) Abaqus model for $\alpha=10^{\circ}$. 


\subsection{Material Properties}

The fabric used in the studied frusta is woven C-glass fiber bonded with epoxy. The areal density of the used woven fabric is $200 \mathrm{~g} / \mathrm{m}^{2}$. Lamina thickness is $0.2 \mathrm{~mm}$ and total laminate thickness is $1.4 \mathrm{~mm}$ for seven layers. The mechanical properties of the lamina are listed in Table 2. The properties of the interface of the bonding epoxy are illustrated in Table 3.

Table 2 Mechanical properties of C-glass/Epoxy composite [24]

\begin{tabular}{|l|c|l|l|}
\hline \multicolumn{1}{|c|}{ Description } & \multicolumn{1}{c|}{ Designation } & \multicolumn{1}{c|}{ Value } & \multicolumn{1}{c|}{ Units } \\
\hline Young's modulus in warp direction & $E_{11}$ & 12246 & $\mathrm{MPa}$. \\
\hline Young's modulus in weft direction & $E_{22}$ & 11339 & $\mathrm{MPa}$. \\
\hline In-plane Poisson's ratio & $v_{12}$ & 0.158 & ------ \\
\hline In-plane shear modulus & $G_{12}$ & 2340 & $\mathrm{MPa}$. \\
\hline Tensile strength in warp direction & $X_{1+}$ & 181.552 & $\mathrm{MPa}$. \\
\hline Ultimate strain in warp direction & $\varepsilon_{1+}^{\text {max }}$ & 0.023293 & ----- \\
\hline Tensile strength in weft direction & $X_{2+}$ & 172.462 & $\mathrm{MPa}$. \\
\hline Ultimate strain in weft direction & $\varepsilon_{2+}^{\text {max }}$ & 0.023089 & ------ \\
\hline In-plane shear strength & $S$ & 39.626 & $\mathrm{MPa}$. \\
\hline
\end{tabular}

\subsection{Mesh and Element Type}

Each layer meshed with average element size of $0.5 \times 1 \mathrm{~mm}$ with thickness of $0.2 \mathrm{~mm}$. Continuum shell (CS8R) elements are used for modeling the orthotropic layers of GFRP material. These elements have a 3D geometry with kinematic and constitutive behavior similar to conventional shell elements [25].

Table 3 Mechanical properties of epoxy interface [26,27]

\begin{tabular}{|c|c|c|c|c|c|c|c|c|}
\hline Designation & $K_{n}=K_{s}=K_{t}$ & $t_{n}^{0}$ & $t_{s}^{0}$ & $t_{t}^{0}$ & $G_{I c}$ & $G_{I I c}$ & $G_{I I I c}$ & $\beta$ \\
\hline Value & $10^{6}$ & 39 & 50 & 50 & 0.22 & 0.36 & 0.36 & 1.45 \\
\hline Units & $\mathrm{N} / \mathrm{mm}^{3}$ & MPa. & MPa. & MPa. & $\mathrm{N} / \mathrm{mm}$ & $\mathrm{N} / \mathrm{mm}$ & $\mathrm{N} / \mathrm{mm}$ & --- \\
\hline
\end{tabular}

\subsection{Mass Scaling}

At the beginning of the analysis the mass of the studied structure can be increased by three orders of the original magnitude using fixed mass scaling capability which is available in Abaqus explicit [23]. This technique similar to increasing the loading velocity artificially, both approaches are used to achieve reasonable calculation run time without affecting the final results significantly. To ensure these artificial increases of mass and velocity without affecting the simulation outcomes considerably, a comparison between the strain and kinetic energies is performed to ascertain that the quasi-static condition is accomplished properly.

\section{RESULTS AND DISCUSSION}

Experimental and simulation results obtained through this research work are summarized in the following Para.

\subsection{Damage Mechanism}

Visually the crushed frusta showed different types of fragment formation and damage modes. Damage zone formed ahead the crushing crosshead with maximum spread about $7 \mathrm{~mm}$. Mix of fronds and strips formation damage modes are observed on tested frusta. Fronds are mix of detached tiny particles, large chunks (strip shaped) and severely damaged laminae. Fronds emerge from the damage zone about $2 \mathrm{~mm}$ ahead the crushing crosshead. Inward accumulation 
of debris in the $10^{\circ}$ is more than $5^{\circ}$ frusta while outward debris accumulation is less than the inward for both configurations. Relatively large pieces of fragments strip shaped generated by growth of crack parallel to the crosshead. These strip shaped fragments are formed due to shear effect with $3-7 \mathrm{~mm}$ width and maximum observed length is $35 \mathrm{~mm}$. The strip shaped debris is pealed outward and inward as crust with thickness less than the structure thickness see Figure 4. No local buckling observed during the crushing process. The enclosed areas in the red lines Figure $4(a-d)$ are showing examples of the fronds formation and the enclosed areas in the black lines are showing examples of the strip shaped debris. The constant speed of the simulated crushing surface caused the large portion of the debris to separate easily and move away from the crushing zone; while experimentally most debris are still connected to the intact frusta portions. The simulation crushing velocity is low enough to ensure the small and negligible effects on the final results [23]. Speeding up the crushing velocity is to decrease simulation time and save computational cost. Damage modes like fronds formation, strip shaped crusts, peripheral cracks and delamination are reproduced in the simulation models as shown in Figure $5(a$ and $b)$.

\subsection{Crashworthiness Characteristics}

The experimental force-displacement graphs for $5^{\circ}$ and $10^{\circ}$ angled frusta configurations are shown in Figure $6(a)$ and the energy-displacement graph is shown in Figure $6(b)$. The experimentally and numerically obtained crashworthiness parameters are illustrated in Table 4 while normalized values are presented in Figure 9. The $5^{\circ}$ frusta showed higher energy absorption and higher SEA than $10^{\circ}$. Experimental and simulation force-displacement graphs for $5^{\circ}$ and $10^{\circ}$ angled frusta are shown in Figure $7(a)$ and $8(a)$ while the energy-displacement graphs are shown in Figure 7(b) and 8(b).

Table 4 Crashworthiness parameters

\begin{tabular}{|l|l|l|l|l|l|}
\hline Parameter & Units & Exp.-50 $^{0}$ & Sim.-50 & Exp.-10 & Sim.-10 \\
\hline$P_{m}$ & $\mathrm{kN}$ & 10.81 & 10.41 & 8.27 & 7.61 \\
\hline$E_{a b}$ & $\mathrm{~N} . \mathrm{m}$ & 757.1 & 729.2 & 579.2 & 531.9 \\
\hline$S E A$ & $\mathrm{~kJ} / \mathrm{kg}$ & 22.95 & 22.1 & 20.5 & 18.9 \\
\hline
\end{tabular}

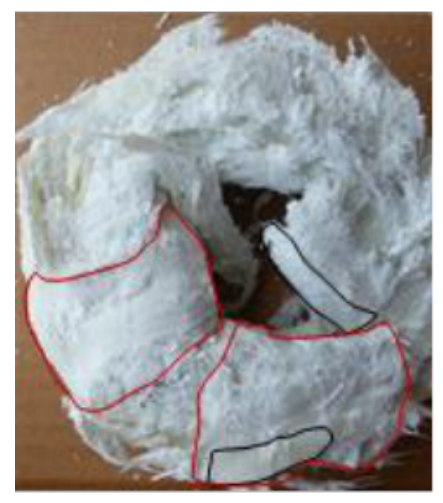

(a)

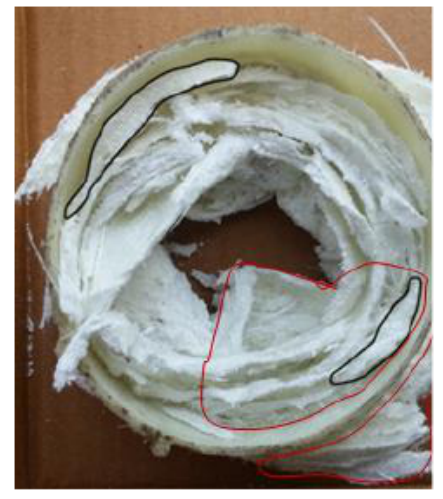

(b)

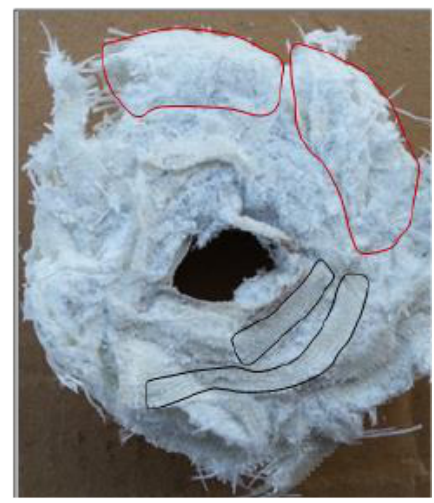

(c) 


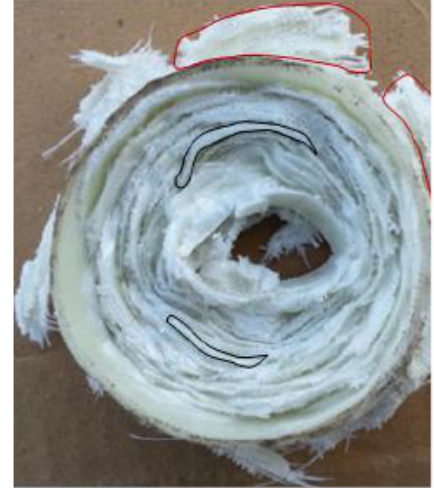

(d)

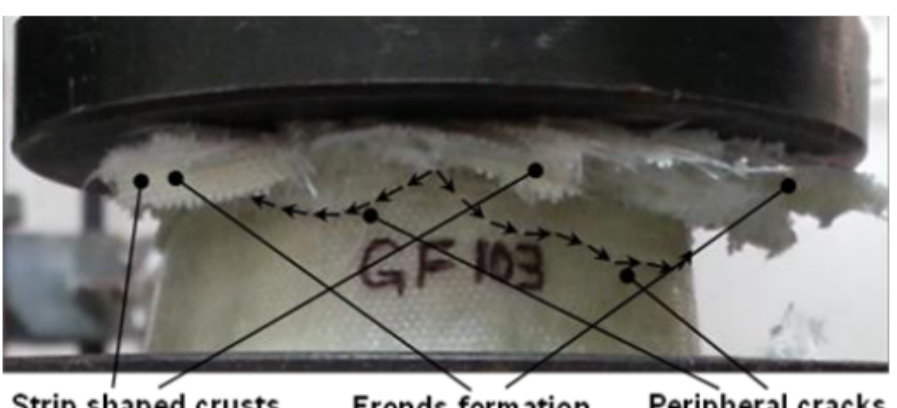

Fronds form ation
Peripheral cracks

(e)

Figure 4. Frusta crushing patterns for: (a) $\alpha=5^{\circ}$ top view; (b) $\alpha=5^{\circ}$ bottom view; (c) $\alpha=$ $10^{\circ}$ top view; (d) $\alpha=10^{\circ}$ bottom view; (e) $\alpha=10^{\circ}$ front view..

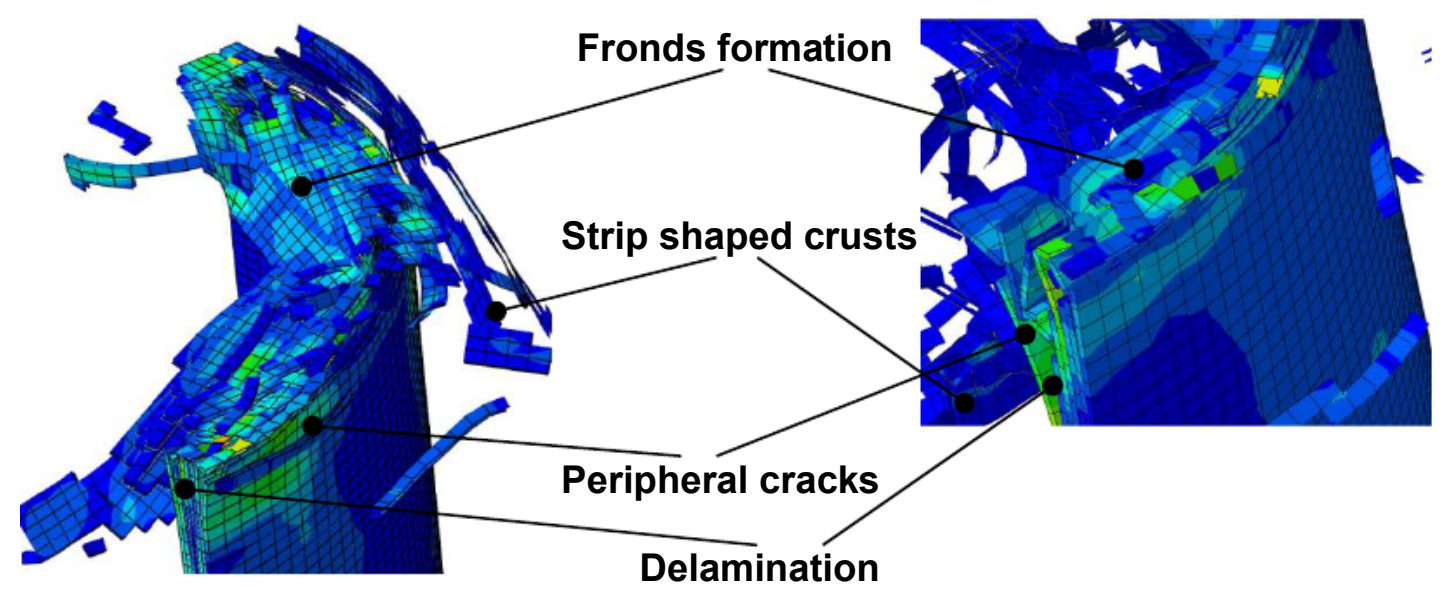

(a)

(b)

Figure 5. Simulation damage modes for: (a) $\alpha=5^{\circ}$ frustum; (b) $\alpha=1^{\circ}$ frustum.

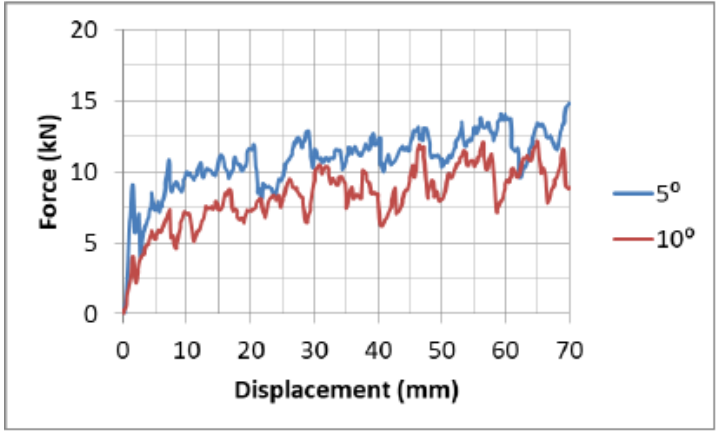

(a)

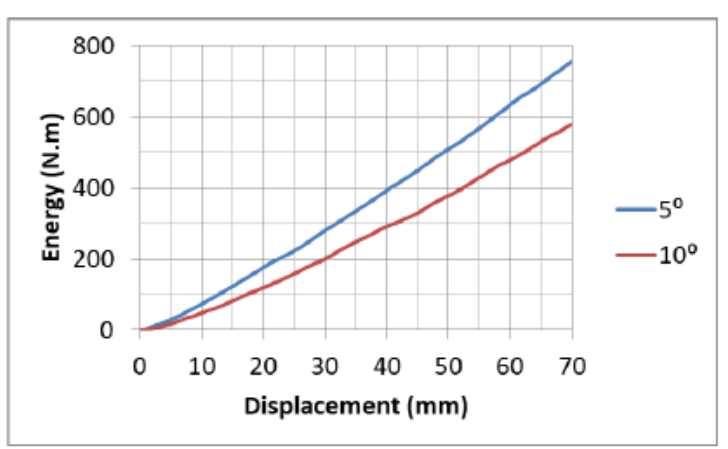

(b)

Figure 6. Experimental results for: $(a)$ force-displacement; $(b)$ energy-displacement. 


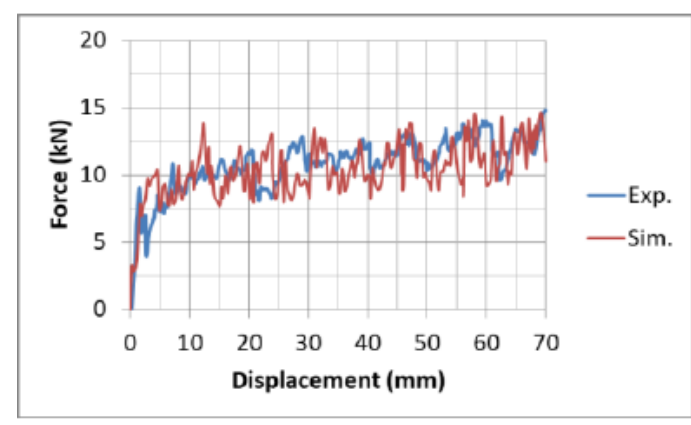

(a)

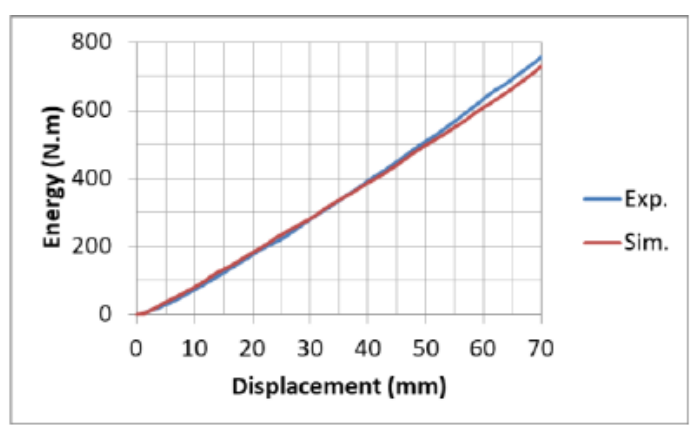

(b)

Figure 7. Experimental and simulation results for $\alpha=5^{\circ}:(a)$ force-displacement; (b) energydisplacement.

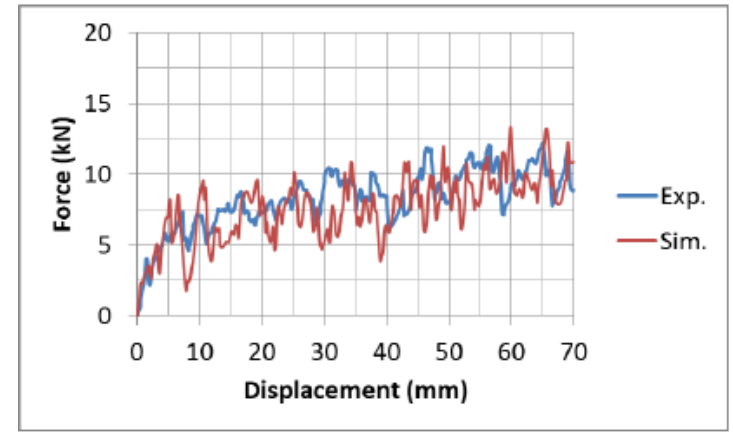

(a)

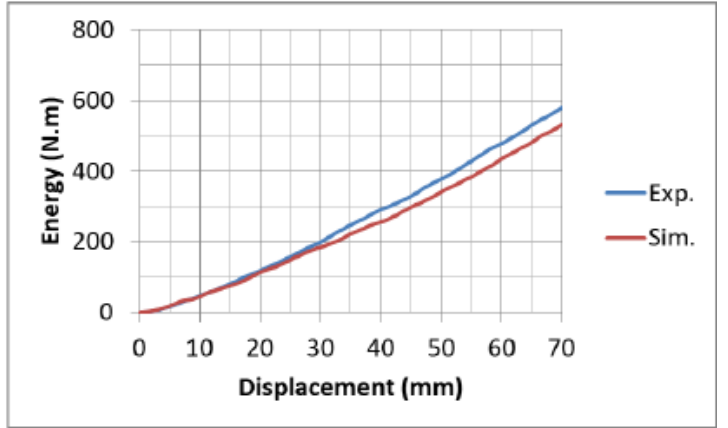

(b)

Figure 8. Experimental and simulation results for $\alpha=10^{\circ}:(a)$ force-displacement; $(b)$ energy-displacement.

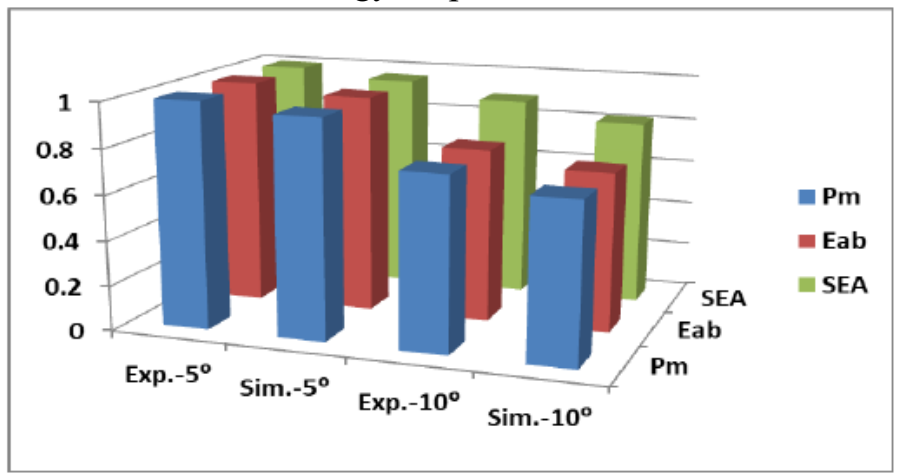

Figure 9. Normalized experimental and simulation crashworthiness parameters.

\section{CONCLUSIONS}

In this work experimental and numerical crashworthiness analysis of GFRP frusta structures are performed. These frusta are tested under quasi-static condition and analyzed numerically using Abaqus 6.19 explicit solver. Progressive damage observed for all tested specimens. $5^{\circ}$ frusta configuration showed better crashworthiness performance than $10^{\circ}$ ones. The simulations showed good agreement with experimental results where the strip shaped fragments formation along with tiny debris are reproduced numerically. Reaction force and energy absorption characteristics obtained experimentally and numerically are in good agreement. This shows the robustness of simulation techniques. 


\section{REFERENCES}

[1] Juan A. Hurtado Ireneusz Lapczyk, "Progressive damage modeling in fiber-reinforced materials," Composites: Part A, vol. 38, 2007 pp. 2333-2341.

[2] Benjamin Liaw, Feridun Delale, Basavaraju B. Raju Ercan Sevkat, "A combined experimental and numerical approach to study ballistic impact response of S2-glass fiber/toughened epoxy composite beams," Composites Science and Technology, vol. 69, 2009. pp. 965-982,

[3] Suhail Ahmad Aswani Kumar Bandaru, "Modeling of progressive damage for composites under ballistic impact," Composites part B, vol. 93, 2016. pp. 75-87,

[4] S. Ramesh F. Tarlochan, "Composite sandwich structures with nested inserts for energy absorption application," Composite Structures, vol. 94, 2012 pp. 904-916.

[5] Jürgen Pleitner, Henk de Boer, Clarice Carmone Peter Linde, "Modelling and Simulation of Fibre Metal Laminates," in The 17th annual ABAQUS Users' Conference, Boston, MA, USA, 2004.

[6] Farid Taheri, Neil Pegg, You Lu Haipeng Han, "A numerical study on the axial crushing response of hybrid pultruded and \pm 45 braided tubes," Composite Structures, vol. 80, 2007 pp. 253-264.

[7] Y.S. Byun, T.W. Ku, W.J. Song, J. Kim B.S. Kang S.H. Song, "Experimental and Numerical Investigation on Impact Performance of Carbon Reinforced Aluminum Laminates," Journal of Materials Science \& Technology, vol. 26, no. 4, 2010 pp. 327-332.

[8] M.R. Bambach, "Axial capacity and crushing of thin-walled metal, fibre-epoxy and composite metal-fibre tubes," Thin-Walled Structures, vol. 48, 2010 pp. 440-452.

[9] R. Velmurugan M. Buragohaina, "Study of filament wound grid-stiffened composite cylindrical structures," Composite Structures, vol. 93, 2011 pp. 1031-1038.

[10] S. Sulaiman, A.M.S. Hamouda, E. Mahdi Elfetori F. Abdewi, "Effect of geometry on the crushing behaviour of laminated corrugated composite tubes," Journal of Materials Processing Technology, vol. 172, 2006 pp. 394-399.

[11] J. Díaz, L. Romera, M. Costas J. Paz, "Crushing analysis and multi-objective crashworthiness optimization of GFRP honeycomb-filled energy absorption devices," Finite Elements in Analysis and Design, vol. 91, 2014 pp. 30-39.

[12] Jung Ju Lee, Ku Hyun Kim, Min Cheol Song, Jeung Soo Huh Kum Cheol Shin, "Axial crush and bending collapse of an aluminum/GFRP hybrid square tube and its energy absorption capability," Composite Structures, vol. 57, 2002 pp. 279-287.

[13] K. Manisekar, V. Manikandan M. Kathiresana, "Performance analysis of fibre metal laminated thin conical frusta under axial compression," Composite Structures, vol. 94, 2012 pp. 35103519 .

[14] K. Manisekar, V. Manikandan M. Kathiresana, "Crashworthiness analysis of glass fibre/epoxy laminated thin walled composite conical frusta under axial compression," Composite Structures, no. 108, 2014 pp. 584-599.

[15] Yiru Ren, Jinwu Xiang Hongyong Jiang, "A numerical study on the energy-absorption offibre metal laminate conical frusta under quasi-static compression loading," Thin-Walled Structures, vol. 124, 2018 pp. 278-290.

[16] 3DS SIMULIA, ABAQUS 6.14 Analysis User's Guide Volume Iii: Materials. United States: 3DS Dassault Systèmes, 2014.

[17] A. Rotem Z. Hashin, "A Fatigue Criterion for Fiber-Reinforced Materials," Journal of Composite Materials, vol. 7, no. 4, 1973 pp. 448-464.

[18] Z. Hashin, "Failure Criteria for Unidirectional Fiber Composites," Journal of Applied Mechanics, vol. 47, 1980 pp. 329-334.

[19] J. Lubliner, R.L. Taylor A. Matzenmiller, "A constitutive model for anisotropic damage in fibercomposites," Mechanics of Materials, vol. 20, no. 2, 1995 pp. 125-152. 
[20] Carlos G. Davila Pedro P. Camanho, "Mixed-Mode Decohesion Finite Elements for the Simulation of Delamination in Composite Materials," United States, 2002.

[21] A.F.Johnson, "Modelling fabric reinforced composites under impact loads," Composites Part A: Applied Science and Manufacturing, vol. 32, no. 9, 2001 pp. 1197-1206.

[22] Pere Maimí, Pedro P. Camanho, Joan-Andreu Mayugo, Carlos G. Dávila, "A thermodynamically consistent damage model for advanced composites," United States, Technical Report 2006.

[23] Kyle C.Indermuehle, Juan A.Hurtado Vladimir S.Sokolinsky, "Numerical simulation of the crushing process of a corrugated composite plate," Composites Part A: Applied Science and Manufacturing, vol. 42, no. 9, September 2011 pp. 1119-1126.

[24] R. Zahari, D.L. Majid, F. Mustapha, M.T.H. Sultan and A.S.M. Rafie N. Yidris, "Crush Simulation Of Woven C-Glass/Epoxy Unmanned Ariel Vehicle Fuselage Section," International Journal of Mechanical and Materials Engineering, vol. 5, no. 2, 2010 pp. 260267.

[25] 3DS SIMULIA, ABAQUS 6.14 Analysis User's Guide Volume Iv: Elements. United States: 3DS Dassault Systèmes., 2014.

[26] Sanan H. Khan, Venkitanarayanan Parameswaran Ankush P. Sharma, "Experimental and numerical investigation on the uni-axial tensile response and failure offiber metal laminates," Composites Part B, vol. 125, 2017 pp. 259-274.

[27] Ankush P. Sharma, Rajesh Kitey, Venkitanarayanan Parameswaran Sanan H. Khan, "Effect of metal layer placement on the damage and energy absorption mechanisms in aluminium/glassfibre laminates," International Journal of Impact Engineering, vol. 119, 2018 pp. 14-25.

[28] Devendiran.S, Manivannan K, Venkatesank, Arun Tom Mathew, Abhijeet Thakur, and Ashish Chauhan V, Free Vibration of Damaged and Undamaged Hybrid cfrp/Gfrp Composite Laminates, International Journal of Mechanical Engineering and Technology (IJMET), Volume 8, Issue 8, August 2017, pp. 349-360.

[29] Alekhya N and N Prabhu Kishore, Performance Comparison of GFRP Composite I Section with an Aluminum I Section. International Journal of Civil Engineering and Technology, 8(4), 2017, pp. 278-286.

[30] T. P. Meikandaan and Dr. A. Ramachandra Murthy, Retrofittng of Reinforced Concrete Beams Using GFRP Overlays. International Journal of Civil Engineering and Technology, 8(2), 2017, pp. 410-417

[31] Piyush P. Gohil, Vijaykumar Chaudhary and Kundan Patel, Significance of Drilling Parameters on Delamination Factor in GFRP: An Image Analysis Approach, International Journal of Mechanical Engineering and Technology (IJMET), Volume 3, Issue 2, May-August (2012), pp. 200-209. 